\title{
Изучение гидратационных свойств полимерных суперабсорбентов, используемых в сельском хозяйстве
}

\author{
Семенов В.Н. ${ }^{1}$, Зенищева А.В. ${ }^{1}$, Селеменев В.Ф. ${ }^{1}$, Кузнецов В.А. ${ }^{1}$, \\ Лавлинская М.С. ${ }^{1}$, Лукин А.Л. ${ }^{2}$, Сорокин А.В. ${ }^{1}$ \\ ${ }^{1}$ Воронежский государственный университет, Воронеж \\ ${ }^{2}$ Воронежский государственный аграрный университет имени императора Петра I, Воронеж
}

Поступила в редакцию 25.04.2018 г.

DOI: https://doi.org/10.17308/sorpchrom.2018.18/595

В настоящей работе исследованы гидратационные свойства суперабсорбентов «Твердая вода» различного состава, а также товарных продуктов, применяемых в сельском хозяйстве «SolidRain» (Мексика), «AquaSource» (Армения), «Аквасин» (Казань, Россия) и «AquaSorb» (Франция). Определена их предельная степень набухания в дистиллированной воде, а также в кислой и щелочных средах. Изучена кинетика процесса высвобождения поглощенной воды. В результате эксперимента установлено, что наилучшие показатели по набуханию достигаются в дистиллированной воде и кислой среде для всех образцов, кроме «Твердая вода», тип I, максимальное водопоглощение для которого происходит в щелочной среде. Изучение кинетики высвобождения сорбированной воды показало, что процесс более быстро протекает после набухания в щелочной или кислой средах.

Ключевые слова: суперабсорбенты, степень набухания, кинетика высвобождения

\section{The study of hydration properties of the superabsobents used in agriculture}

\author{
Semenov V.N. ${ }^{1}$, Zenishcheva A.V. ${ }^{1}$, Selemenev V.F. ${ }^{1}$, Kuznetsov V.A. ${ }^{1}$, \\ Lavlinskaya M.S. ${ }^{1}$, Loukine A.L. ${ }^{2}$, Sorokin A.V. ${ }^{1}$ \\ ${ }^{1}$ Voronezh State University, Voronezh \\ ${ }^{2}$ Voronezh State Agrarian University named after Emperor Peter the Great, Voronezh
}

The aim of this work is study of the hydration properties of the polymeric superabsorbent (SA) used in agrotechnology such as Tverdaya Voda (type I and type II) developed in Voronezh State University and commercial products SolidRain (Mexica) AquaSorb (France), AquaSource (Armenia), Aquasin (Russia). The difference between type I and type II for Tverdaya Voda SAs is a kind of the used cross-linker: $N, N$-methylenebis-acrylamide for type I, and ethyleneglycol dimethacrylate for type II. Experiments for swelling ratio, $\omega$, determination were carried out in deionized water, $0.1 \mathrm{M} \mathrm{NaOH}$ and $0.1 \mathrm{M} \mathrm{HCl}$ water solutions via weight mode. Found that the maximal swelling ratio is reached in water and acidic medium. Only Tverdaya Voda, type I has the highest $\omega$ value in alkaline medium (Table 1). Absorbed water release kinetics was researched via gravimetric analysis at $65{ }^{\circ} \mathrm{C}$. Established that water loss is rapider after swelling in acidic or alkaline media, but mexican SolidRain has dramatically fast water loss after swelling in deionized water (Fig. 1-3). That is why it can't be used for acid soil. Tverdaya Voda superabsprbents have smooth water loss profile that make their universal material that can be used for all soil type. Tverdaya Voda type I due to the highest swelling ratio in alkaline medium is the most appropriate SA for Voronezh leached chernozem. To sum up, swelling ratio and water release kinetics were researched for some SAs used in agro technology. Found that mexican SolidRain don't belongs for acid soil, and Tverdaya Voda type I is appropriate for leached soil.

Keywords: superabsorbents, swelling ratio, water release kinetics 


\section{Введение}

Суперабсорбенты (CA) - сетчатые гидрофильные полимеры, способные к поглощению воды в количествах, в несколько сотен раз превосходящих их массу, находят широкое применение в различных областях деятельности человека. Они используются для создания впитывающих гигиенических материалов, таких как подгузники, прокладки, впитывающее белье и салфетки, ландшафтном дизайне, бурильных работах и др [1-8].

Одной из самых перспективных сфер применения таких материалов является сельское хозяйство [1-3, 8]. Ввиду резко меняющихся климатических условий проблема экономии пресной воды и сохранения влаги в почвах в период вегетации растений стоит чрезвычайно остро в ряде регионов Российской Федерации и стран ближнего и дальнего зарубежья. Благодаря способности суперабсорбентов поглощать избыточную воду, а затем постепенно отдавать ее, использование таких «полимерных резервуаров» позволяет не только сохранить и имеющуюся в почве влагу, но и сократить объемы воды, требуемой для полива возделываемых культур. Отдельно стоит отметить, что использование СА способствует повышению урожайности растений и улучшению микробиологической активности почв. Так, например, урожай ячменя, полученный с использованием биодеградируемого суперабсорбента «Твердая вода» в количестве 20 кг/га, более чем на 25\% превышал аналогичный показатель для культуры, выращиваемой с капельным поливом [9]. Кроме того, за счет присутствия в полимере азотсодержащих биодеградрумеых звеньев, в полтора раза повышаются наиболее значимые показатели микробиологической активности почв [10]. Таким образом, использование суперабсорбентов способствует удешевлению агротехнологии за счет сокращения расходов на полив, повышению урожайности культур и улучшения качества почв.

В связи с высокой эффективностью применения суперабсорбентов в сельском хозяйстве, представляет интерес провести сравнительный анализ основных потребительских характеристик различных товарных суперабсорбентов. Цель данной работы - провести сравнительный анализ влагопоглощающих свойств суперабсорбентов «Твердая Вода» (Воронеж, Россия), «SolidRain» (Мексика), «AquaSource» (Армения), «Аквасин» (Казань, Россия) и «AquaSorb» (Франция).

\section{Эксперимент}

Объектами исследования являются образцы различных товарных суперабсорбентов - «SolidRain» (Мексика), «AquaSource» (Армения), «Аквасин» (Казань, Россия) и «AquaSorb» (Франция). Согласно информации, представленной производителями, эти материалы представляют собой сетчатые полимеры на основе акриламида и/или солей акриловой кислоты.

Также объектом исследования является суперабсорбент «Твердая вода» - разработка коллектива ученых химического факультета ВГУ. В отличие от представленных товарных сорбентов, в состав «Твердой воды» входят биодеградируемые полисахаридные звенья, повышающие экологичность продукта. В работе представлены два типа «Твердой воды», полученные согласно [11], различающиеся типом использованного сшивающего агента.

Влагопоглащающую способность СА исследовали весовым методом. Навеску образца $(0.2000 \pm 0.0002 \Gamma)$ последовательно помещали в $200 \mathrm{~cm}^{3}$ дистиллированной воды или $0.1 \mathrm{M}$ растворы $\mathrm{HCl}$ и $\mathrm{NaOH}$. Образцы оставляли на 8 часов для достижения равновесия. Затем образцы отделяли от жидкой фазы, помещали в сушильный шкаф и выдерживали при температуре $65{ }^{\circ} \mathrm{C}$. Через каждые 15 минут образец извлекали и 
взвешивали. Эксперимент продолжали до достижения полимерами постоянной массы. Степень набухания, $\omega$, рассчитывали по формуле [12]:

$$
\omega=\frac{\left(m_{1}-m_{2}\right)}{\left(m_{1}-m_{0}\right)} \cdot 100 \%
$$

где $m_{1}$ - масса бюкса с сорбентом до высушивания, г; $m_{2}$ - масса бюкса с сорбентом после высушивания, г; $m_{0}$ - масса пустого бюкса, г.

На основании полученных экспериментальных данных строили графические зависимости потери массы от времени.

\section{Обсуждение результатов}

Предельную способность набухания образцов различных СА исследовали в трех различных условиях: в дистиллированной воде ( $\mathrm{pH}=5.5 \pm 0.2)$, а также щелочной и кислых средах. Такой выбор условия обусловлен тем, что почвы, в которых могут использоваться эти сорбенты, также характеризуются широким значением величин $\mathrm{pH}$. Результаты исследования представлены в таблице 1.

Таблица 1. Степень набухания образцов суперабсорбентов

\begin{tabular}{|c|c|c|c|c|}
\hline \multirow{2}{*}{$№$ п/п } & \multirow{2}{*}{ Суперабсорбент } & \multicolumn{3}{|c|}{ Степень набухания, $\omega, \%$} \\
\cline { 3 - 5 } & & $\begin{array}{c}\text { Дистиллированная } \\
\text { вода }\end{array}$ & $0.1 \mathrm{M} \mathrm{HCl}$ & $0.1 \mathrm{M} \mathrm{NaOH}$ \\
\hline 1 & Твердая вода, тип I & 98.90 & 97.10 & 112.86 \\
\hline 2 & Твердая вода, тип II & 98.63 & 92.48 & 98.03 \\
\hline 3 & SolidRain & 99.54 & 96.07 & 69.46 \\
\hline 4 & AquaSource & 96.64 & 95.77 & 109.36 \\
\hline 5 & Aквасин & 97.17 & 97.19 & 96.77 \\
\hline 6 & AquaSorb & 98.11 & 97.13 & 96.30 \\
\hline
\end{tabular}

Как видно из приведенных данных, все исследуемые образцы имеют практически одинаковые показатели степени набухания. Однако, в кислой и щелочной средах значение $\omega$ для большинства сорбентов несколько меньше по сравнению с величиной, полученной в дистиллированной водой. В этом случае воздействие на структуру воды оказывают влияние как неэлектролиты (гидроксильные группы полисахарадных звеньев), так и электролиты (-COO$\left.{ }^{-}, \mathrm{Na}^{+},-\mathrm{NH}_{3}{ }^{+}, \mathrm{Cl}^{-}\right)$[13-14]. Среди полученных нами образцов сорбентов «Твердая вода» наилучшие показатели по набуханию показал образец «Твердой воды» тип I, при синтезе которого использован гидрофильный сшивающий агент $N, N$-метилен-бис-акриламид. Также этот образец характеризуется наивысшими показателями по величине $\omega$ в щелочной среде, что обусловлено электростатическим отталкиванием диссоциированных карбоксильных групп, образующихся в результате гидролиза акриламида. Это делает его пригодным для использования в выщелоченных почвах, например, черноземе Воронежской области.

Кроме способности к водопоглощению не менее важной характеристикой является и способность к водоотдаче. На рис. 1-3 представлены зависимости потери массы от времени при $65^{\circ} \mathrm{C}$.

Наиболее резкой потерей поглощенной влаги характеризуются мексиканский copбент «SolidRain», а кривые для сорбентов «Твердая вода» имеют более плавную форму. Резкая потеря влаги в почве может привести к нежелательным последствия, например, к загниванию семян и заболачиванию [9-10].

После набухания в кислой среде потеря влаги всеми исследуемыми образцами протекает более быстро по сравнению с процессом в дистиллированной воде, а для образца мексиканского сорбента - наоборот, кривая носит более плавный характер. В 
настоящее время отсутствуют полные данные о структурных состоявляющих сорбентов «SolidRain», «AquaSource», «Аквасин» и «AquaSorb». Поэтому достоверные предположения о влияние $\mathrm{pH}$ среды на водопоглощающие способности и набухание полимеров можно сделать для суперабсорбентов «Твердая вода». Полимерную сетку образцов «Твердой воды» образуют полисахаридные звенья и остатки акриламида, обуславливающие наличие амидных и карбоксильных групп.

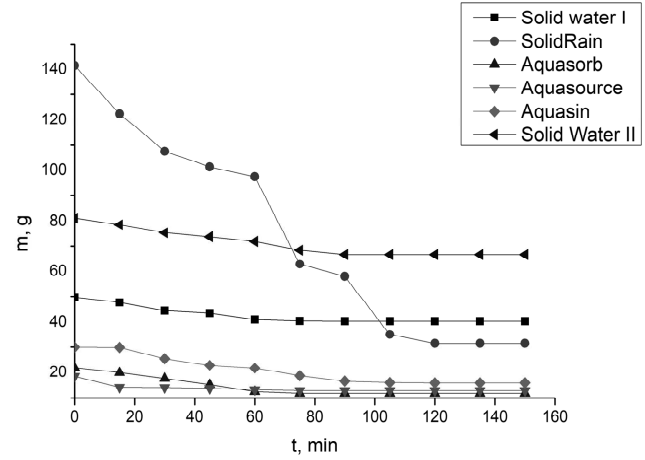

Рис. 1. Зависимость потери массы от времени образцов, набухших в дистиллированной воде

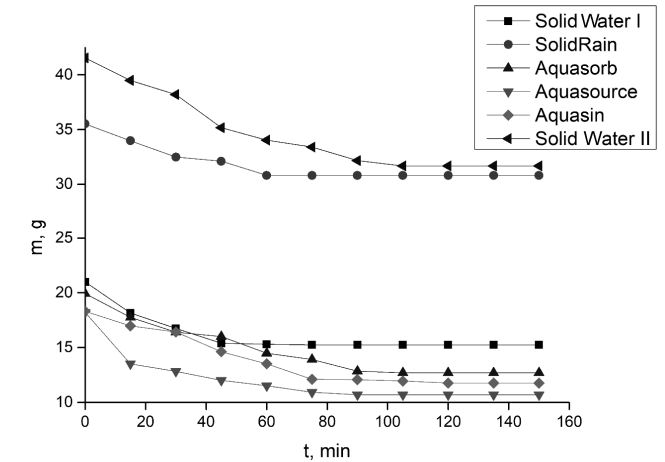

Рис.2. Кривые потери массы сорбентов, набухших в кислой среде.

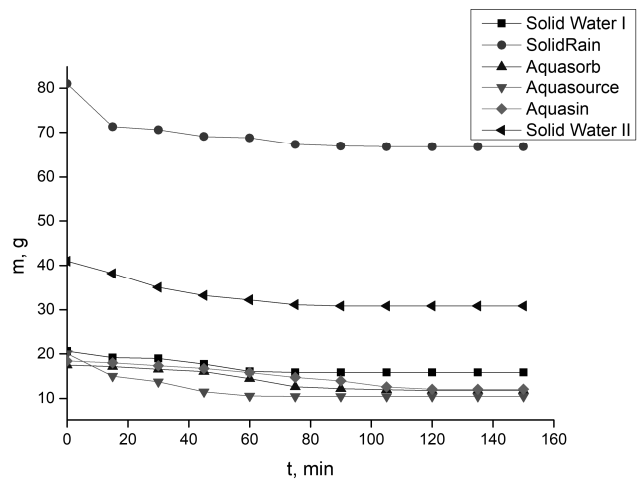

Рис. 3. Кривые потери массы сорбентов, набухших в щелочной среде.

Влияние ОН-групп полисахаридных групп на формирование гидратных структур позволяет рассматривать влагопоглощение как процесс разупорядочивания (разрушения) ассоциатов «вода-вода» во всех областях концентраций. Однако при максимальном влагопоглощении структуру воды необходимо считать однородной, т.е. молекулы воды находятся в едином каркасе с частично заполненными пустотами [14]. Присутствие карбоксильных и амино-групп позволяет рассматривать СА как амфолиты [13], способные существовать в катионной (кислая среда), в биполярной (pH=7) и анионной формах:

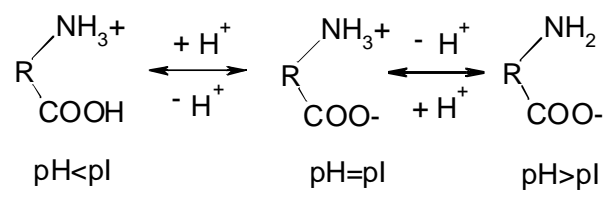

где $\mathrm{pI}$ - изоэлектрическая точка.

Переход из одной ионной формы в другую происходит с участием молекул воды и сопровождается образованием первого гидратного слоя (ближняя гидратация) [14]:

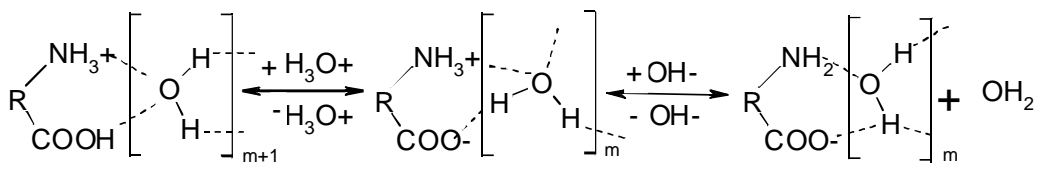


Дальнейшее поглощение воды сорбентом (дальняя гидратация) происходит за счет образования Н-связей между молекулами растворителя. Следует учитывать, что в идеальном случае формирование первого гидратного слоя для биполярной формы менее вероятно по сравнению с катионной и анионной формами [13].

Стоит отметить, что на основании полученных экспериментальных данных можно заключить, что все исследуемые образцы могут успешно использоваться в регионах с сильно закисленными почвами. Кривые потери влаги в щелочной среде также имеют гладкую и пологую форму для всех исследуемых образцов, а также характеризуются наименьшим временем выхода на плато, т.е. процесс водоотдачи для исследуемых образцов наиболее быстро протекает в щелочной среде. На основании проведенных экспериментов можно сделать вывод, что наиболее целесообразно в условиях выщелоченных почв применять суперабсорбент «Твердая вода» тип I, характеризующийся наивысшей степенью набухания в щелочной среде.

\section{Заключение}

Таким образом, исследования показали, что все исследуемые образцы суперабсорбентов имеют практически одинаковые величины степени набухания в кислой среде, в то время как в щелочной этот показатель несколько уменьшается для всех образцов, кроме «Твердая вода», тип I. Установлено, что процесс отдачи влаги быстрее протекает после набухания в кислой или щелочной средах. Мексиканский суперабcopбент «SolidRain» характеризуется наиболее резкой влагоотдачей после набухания в дистиллированной воде, что может негативно сказаться на выращиваемых в условиях слабокислых почв культурах, а также привести к заболачиванию сельскохозяйственных угодий. В регионах с выщелоченными почвами наиболее эффективным сорбентом проявит себя «Твердая вода», тип I, характеризующийся наибольшим набуханием в щелочной среде и равномерной водоотдачей.

Работа выполнена при поддержке «Фонда содействия развитию малых форм предприятий в научно-технической сфере (Фонд содействия инновациям)», договор № 2598 ГC1/41289 om 18.07.2018

\section{Список литературы}

1. Sharma J., Sukriti, Kaith B.S. et al. // $J$ Polym Environ. 2017. Vol. 25. No 1.pp. 1-14. doi:10.1007/s10924-017-0959-8

2. Rojas-Oviedo I., Rodrı'guez-Herna'ndez S., Ca'rdenas J. et al. // J Porous Mater. 2016. Vol. 23. P. 1495-1505. doi: 10.1007/s10934-0160210-3

3. Mohammed A.D., Young D.A., Vosloo H.C.M. // Res Chem Intermed. 2016. Vol. 42. pp. 1-14. doi: 10.1007/s11164-016-2754-x

4. Raymundi V. C., Aguiar L.G., Souza E.F. et al. // Heat Mass Transfer. 2016. Vol. 52. pp. 2193-2201. doi: 10.1007/s00231-015-1732-y

5. Angar N.-E., Aliouche D. // Polym Sci. Ser A. 2016. Vol. 58. No 4. pp. 541-549. doi: 10.1134/S0965545X16040015

6. Wan T., Xiong J., Zhao Q., et al. // Polym Bull. 2016. Vol. 73. pp. 1447-1458. doi: 10.1007/s00289-015-1557-3
7. Xie Yu., Wang A. // J Polym Res. 2009. Vol. 16. pp. 143-150. doi: 10.1007/s10965-0089212-4

8. Agnihotri S., Singhal R. // J Polym Environ. 2017. Vol. 25. pp. 39-52. doi: 10.1007/s10924017-0956-y

9. Лукин А.Л., Мараева О.Б., Кузнецов В.А. и др. // Аграрная наука. 2017. № 9-10. С. 1113.

10.Лукин А.Л., Мараева О.Б., Кузнецов В.А. и др. // Вестник Воронежского государственного аграрного университета. 2018. Т. 11. № 2. C. 35-42. doi: 10.17238/issn20712243.2018.2.35

11.Кузнецов В.А., Селеменев В.Ф., Семенов В.Н., Бакалова М.В. Способ получения гидрофильного сшитого полимера со свойствами суперабсорбента. Патент РФ № 2574722. Опубл. 10.02.2016. Б.И. № 4. 
12.Кузнецов В.А., Лавлинская М.С., Останкова И.В. и др. // Сорбиионные и хроматграфические прочессы. 2017. Т. 17. № 3. С. 484489.

13. Селеменев В.Ф., Рудаков О.Б., Славинская Г.В., Дроздова Н.В. Пигменты пищевых

\section{References}

1. Sharma J., Sukriti, Kaith B. S. et al., $J$ Polym Environ., 2017, Vol. 25, No 1, pp. 1-14. doi:10.1007/s10924-017-0959-8

2. Rojas-Oviedo I., Rodrı'guez-Herna'ndez S., Ca'rdenas J. et al., J Porous Mater., 2016, Vol. 23, pp. 1495-1505. doi: 10.1007/s10934-0160210-3

3. Mohammed A.D., Young D.A., Vosloo H.C.M., Res Chem Intermed., 2016, Vol. 42, pp 1-14. doi: 10.1007/s11164-016-2754-x

4. Raymundi V. C., Aguiar L.G., Souza E.F. et al., Heat Mass Transfer, 2016, Vol. 52, pp. 2193-2201. doi: 10.1007/s00231-015-1732-y

5. Angar N.-E., Aliouche D., Polym Sci. Ser A, 2016, Vol. 58, No 4, pp. 541-549. doi: 10.1134/S0965545X16040015

6. Wan T., Xiong J., Zhao Q., et al., Polym Bull., 2016, Vol. 73, pp. 1447-1458. doi: 10.1007/s00289-015-1557-3

7. Xie Yu., Wang A., J Polym Res., 2009, Vol. 16, pp. 143-150. doi: 10.1007/s10965-008-92124

8. Agnihotri S., Singhal R., J Polym Environ., 2017, Vol. 25, pp. 39-52. doi: 10.1007/s10924017-0956-y

Семенов Виктор Николаевич - д.х.н., заведующий кафедрой общей и неорганической химии ВГУ, Воронеж, тел.: +74732208404

Зенищева Анна Витальевна - аспирант 3 года обучения кафедры общей и неорганической химии ВГУ, Воронеж

Селеменев Владимир Федорович - д.х.н., заведующий кафедрой аналитической химии ВГУ, Воронеж

Кузнецов Вячеслав Алексеевич - д.х.н., профессор кафедры высокомолекулярных соединений и коллоидной химии ВГУ, Воронеж

Лавлинская Мария Сергеевна - к.х.н., младший научный сотрудник базовой кафедры ЭФКО «Молекулярная биотехнология» ВГУ, Воронеж

Лукин Алексей Леонидович - д.с.-Х.н., заведующий кафедрой биологии и защиты растений ВГАУ, Воронеж

Сорокин Андрей Викторович - магистрант второго года обучения кафедры высокомолекулярных соединений и коллоидной химии ВГУ, Воронеж производств (меланины). М. Де Ли принт, 2008, $246 \mathrm{c}$.

14. Крестов Г.А. Термодинамика ионных процессов в растворах. Л. Химия. 1973. 304 с.

9. Loukine A.L., Maraeva O.B., Kuznetsov V.A. et al., Agrarnaya nauka, 2017, No 9-10, pp. 11-13.

10.Loukine A.L., Maraeva O.B., Kuznetsov V.A. et al., Vestnik of Voronezh State Agrarian University, 2018, Vol. 11, No 2, pp. 35-42. doi: 10.17238/issn2071-2243.2018.2.35

11.Kuznetsov V.A., Selemenev V.F., Semenov V.N., Bakalova M.V. The way of obtaining of hydrophilic cross-linked polymer with superabsorbent properties. Patent of Russian Federation № 2574722. Published 10.02.2016. B.I. No 4.

12.Kuznetsov V.A., Lavlinskaya M.S., Ostankova I.V. et al., Sorbcionnye i khromatograficheskie protsessy, 2017, Vol. 17, No 3, pp. 484489.

13.Selemenev V.F., Rudakov O.B., Slavinskaya G.V., Drozdova N.V. Pigmenty pischevykh proizvodstv (melaniny) (Pigments of food industry (melanins), M., DeLi Print, 2008, 246 p (in Russian).

14. Krestov G. A. Termodinamika ionnykh processov $v$ rastvorakh (Thermodynamics of ion process in solutions). Leningrad, Khimiia, 1973, 304 p (in Russian).

Semenov Viktor N. - Dr Sci (Chem), head of common and inorganic chemistry chair of Voronezh State University, Voronezh, e-mail: office@chem.vsu.ru

Zenischeva Anna V. - $3^{\text {rd }}$ year education post-graduate student of common and inorganic chemistry chair of Voronezh State University, Voronezh, e-mail: zenischeva@vsu.ru

Selemenev Vladimir F. - Dr Sci (Chem), head of analytical chemistry chair of Voronezh State University, Voronezh, e-mail: common@chem.vsu.ru

Kuznetsov Vyacheslav A. - Dr Sci (Chem), professor of macromolecules compound and colloid chemistry chair of Voronezh State University, Voronezh, e-mail: dr.v.kuznetsov@gmail.com

Lavlinskaya Maria S. - PhD (Chem), junior researcher of molecular biotechnology chair of Voronezh State University, Voronezh, e-mail: maria.lavlinskaya@gmail.com

Loukine Alexey A. - Dr Sci (Agriculture), head of biology and plant protection chair of Voronezh State Agriculture University named after Emperor Peter I, e-mail: loukine@mail.ru, tel: +74732537788

Sorokin Andrey V. - $2^{\text {nd }}$ year education master student of macromolecules compound and colloid chemistry chair of Voronezh State University, Voronezh, email:pzkmph2@gmail.com 